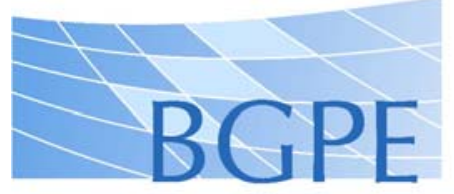

Bavarian Graduate Program in Economics

BGPE Discussion Paper

No. 88

\title{
The Impact of Trade on Employment, Welfare, and Income Distribution in Unionized General Oligopolistic Equilibrium
}

\section{Hartmut Egger \\ Daniel Etzel}

January 2010 


\title{
The Impact of Trade on Employment, Welfare, and Income Distribution in Unionized General Oligopolistic Equilibrium*
}

\author{
Hartmut Egger ${ }^{\dagger}$ \\ Daniel Etzel ${ }^{\ddagger}$ \\ University of Bayreuth \\ University of Bayreuth \\ CESifo and GEP
}

December 17, 2009

\begin{abstract}
This paper sets up a general oligopolistic equilibrium model with unionized labor markets. By accounting for productivity differences, the model features profit and wage differentials across industries. We use this setting to study the impact of trade liberalization on employment, welfare, and the distribution of income. In particular, we show that a movement from autarky to free trade with a symmetric partner country lowers union wage claims and therefore stimulates employment and raises welfare. Whether firms can extract a larger share of rents in the open economy depends on the competitive environment as well as on the degree of centralization in union wage setting. Finally, the distribution of profit income across firm owners remains unaffected, while the distribution of wage income becomes more equal when a country opens up to trade.
\end{abstract}

JEL codes: F12, F16, J51, L13

Keywords: General oligopolistic equilibrium, Unionized labor market, Trade liberalization, Income distribution

\footnotetext{
${ }^{*}$ We are grateful to Carsten Eckel, Udo Kreickemeier, Oliver Lorz, Jens Südekum and participants at the 11th Göttingen Workshop on International Economics, the European Trade Study Group, the Midwest International Economics Meeting, the FIW Research Conference on International Economics as well as seminar participants at the University of Bamberg, the University of Bayreuth, and the University College Dublin for helpful comments and suggestions. We also thank Frank Pisch for excellent research assistance. Daniel Etzel gratefully achnowledges financial support from the Foundation of International Management at the University of Bayreuth.

${ }^{\dagger}$ University of Bayreuth, Department of Law and Economics, Universitätsstr. 30, 95447 Bayreuth, Germany. E-mail: hartmut.egger@uni-bayreuth.de. Phone: +49.921.55-2906. Fax: +49.921.55-842905.

${ }^{\ddagger}$ University of Bayreuth, Department of Law and Economics, Universitätsstr. 30, 95447 Bayreuth, Germany. E-mail: daniel.etzel@uni-bayreuth.de. Phone: +49.921.55-2907. Fax: +49.921.55-842905.
} 


\section{Introduction}

The distributional effects of international trade are a major concern of the general public and policy makers alike. The common fear is that market integration improves the outside opportunities of firm owners and hence limits the possibility of workers to skim a fair share of the rents arising from economic activity (OECD, 2007). This issue has been prominently discussed in a large literature that addresses union wage setting in an international oligopoly (see, e.g., Mezzetti and Dinopoulos, 1991; Naylor, 1998; Lommerud, Meland, and Sørgard, 2003). However, the focus of this literature is on rent sharing at the firm or industry level, while there is no discussion on how trade affects the economy-wide distribution of profit and wage income, an issue that is of primary interest for policy makers who are concerned about the impact of trade on inequality and social justice (Bernanke, 2007; OECD, 2007).

It is the aim of this paper to provide a detailed discussion on how opening up to trade affects the distribution of profit and wage income. For this purpose, we set up a general oligopolistic equilibrium (GOLE) model along the lines of Neary (2009), with a continuum of industries, a small and exogenous number of firms within each sector, Cournot competition, and labor as the only factor of production. To account for rent sharing, we extend the Neary framework and consider union wage setting, similar to Bastos and Kreickemeier (2009). Although our analysis builds on the key insight from Bastos and Kreickemeier (2009) that the trade effects on a unionized oligopoly change substantially when general equilibrium feedback effects are accounted for, there are several important differences between the two approaches. Most importantly, we do not restrict union activity to a subset of sectors but instead assume that it is equally relevant for all industries. This gives rise to involuntary unemployment, which is an important aspect of inequality. ${ }^{1}$ Furthermore, we assume that profits are not distributed to workers but rather accrue to firm owners, who do not work. This assumption allows us to disentangle income inequality between two key groups of economic agents - firm owners and workers - from income inequality within these two groups of individuals, thereby providing a comprehensive picture of how economic rents are distributed. Finally, we account for productivity differences across industries, in order to analyze how and to what extent industry-specific factors govern the distributional effects of trade liberalization. Despite clear supportive evidence for the idea that the interaction of industry-specific factors and rent sharing between firms and unions is an important driving force behind changes in income inequality, this channel of influence has so far not been at the heart of interest in trade theory. ${ }^{2}$

\footnotetext{
${ }^{1}$ As pointed out by Scheve and Slaughter (2001) the risk of job loss is the main concern of workers, regarding the labor market implications of trade liberalization. In view of such observations, Davidson, Martin, and Matusz (1999, p. 272) argue that "trade economists should begin to seriously consider environments in which unemployment is carefully modeled". However, most of the existing studies on union wage-setting in an international trade context do not tackle this issue. For an exception, see Eckel and Egger (2009).

${ }^{2}$ Early contributions that provide evidence for this interaction and its relevance for explaining wage inequality include work by Dickens and Katz (1987), Krueger and Summers (1988), Katz and Summers (1989), and Grey (1993). More recent evidence is provided by Plasman, Tojerow, and Rycx (2006) and Du Caju, Rycx, and Tojerow
} 
We start our analysis by characterizing the unionized GOLE model under autarky. Subsequently, we investigate how firm-level wage setting interacts with unemployment compensation in determining the equilibrium outcome in the closed economy. Thereby, we find that more generous unemployment compensation leads to wage compression and thereby lowers aggregate employment, utilitarian welfare, wage income inequality and the ratio between average profits and average wages, as a measure of inter-group income inequality. The distribution of profit income across firm owners becomes more unequal, because in sectors with low productivity levels unemployment benefits exert a stronger influence on union wage claims than in sectors with high productivity. Furthermore, we also investigate how productivity differences across sectors affect our results. In this respect, the most important insight is that a mean-preserving spread in the technology distribution raises unemployment and thus lowers welfare. This result differs substantially from Neary (2009), where - in view of a perfectly competitive labor market - aggregate employment stays constant, while utilitarian welfare increases as employment shifts towards jobs with higher productivity.

In a second step, we analyze the opening up to free trade with a symmetric partner country. This doubles the number of competitors in each industry, which ceteris paribus lowers profits and hence wage claims of unions by means of a standard rent-sharing mechanism. However, the number of consumers doubles as well. This makes both consumer and labor demand more elastic and further reduces union wage claims. In sum, wages decline when a country opens up for trade. This finding is well in line with previous work on international trade in unionized oligopoly (see Huizinga, 1993; Sørensen, 1993). ${ }^{3}$ With labor markets being more competitive in the open economy, employment is stimulated and hence utilitarian welfare higher than in the closed economy. In contrast to Neary (2009), positive welfare effects do also materialize in a featureless economy, in which both countries are identical and all industries utilize the same production technology. This confirms previous insights that employment adjustment in imperfect labor markets provides an additional source for gains from trade that is different from those in conventional settings (see e.g. Matusz, 1996; Egger, Egger, and Markusen, 2009).

Regarding the outcome of rent sharing, we find that the average worker may gain or lose relative to the average firm owner, with the respective result depending crucially on the market

\footnotetext{
(2008).

${ }^{3}$ Bastos and Kreickemeier (2009) embed this framework into a Neary-type GOLE model in order to check whether and to what extent the the wage reduction in response to trade depends on the assumption of partial equilibrium. They find that in a general equilibrium setting union wages do not necessarily fall if a country moves from autarky to free trade, because wages in sectors with competitive labor markets, and hence the outside income opportunities of workers in unionized industries increase. This effect disappears in our setting since we assume that unions are equally relevant in all industries and unemployment benefits are constant. As a consequence, outside income opportuities of union members do not improve if a country opens up for trade. Beyond the effect of a movement from autarky to trade, Bastos and Kreickemeier (2009) also analyze the implications of a marginal trade liberalization in an already open economy. In this respect, they show that the partial equilibrium wage effects of a small trade cost reduction, as analyzed in Naylor $(1998,1999)$, are reinforced if a full set of general equilibrium feedback effects is accounted for. The impact of a marginal trade liberalization is not addressed in this paper, since the assumption of industry-specific productivity levels renders such an analysis a non-trivial task, which is beyond the scope of this paper and thus left open for future research.
} 
power of producers. On the one hand, wages fall in all industries, which tends to increase income inequality between these two groups of agents. On the other hand, profits may increase or decrease. They increase if the market power of firms within their own industry is large more specifically, if the autarky equilibrium is characterized by a monopolistic or a duopolistic sectoral market structure. In this case, the opening up to trade improves the possibility of firm owners to extract rents, but still raises welfare, because wage claims of unions become more moderate and total employment expands. A similar effect was identified by Huizinga (1993) in a partial equilibrium setting with a monopolistic market structure under autarky. Our analysis however provides the additional insight that in the case of firm-level wage setting the number of competitors must be sufficiently small in order for the positive profit effect to materialize. If competition is already sufficiently intense under autarky, firm owners will lose in absolute terms and relative to the average production worker when a country opens up for trade.

As a further novel result, we show that the distribution of profit income across firm owners does not change in response to trade liberalization. There are two counteracting effects at work. On the one hand, wages fall in all industries, with the respective decline being less pronounced in sectors with low productivity due to wage compression in the presence of unemployment compensation. All other things equal, this makes the distribution of profit income less equal. On the other hand, the employment response to a given wage decline is less pronounced in industries with high productivity, as firms in these sectors produce at a less elastic segment of their labor demand curve. Both effects exactly cancel out in our setting, thereby leaving the distribution of profit income across industries unaffected. This result complements insights from the heterogeneous firms literature, where the opening up to trade exhibits firm-specific effects, with the most productive producers benefiting from access to an export market and the least productive ones losing due to imports from foreign firms (see Melitz, 2003). In our setting product markets are fully integrated and hence all firms are equally exposed to the globalization shock. As a consequence, firm-specific effects of a movement from autarky to free trade do not materialize, so that the distribution of profit income across firms and industries remains unaffected.

As a final aspect of the distributional consequences, we analyze how the opening up to trade affects wage income inequality. There are two principle sources of influence: changes in the wage premium offered by more productive industries and changes in the relative employment levels across industries. We show that a movement from autarky to free trade does not affect the composition of workers across industries, while it lowers the wage premium offered by more productive industries, as the existence of unemployment compensation causes a less than proportional decline in the wage payments of sectors with low productivity. Noting that all workers in our setting are ex ante identical this result contributes to the still small literature that addresses the trade effects on intra-group wage inequality (see e.g Wälde and Weiss, 2007). ${ }^{4}$ In particular,

\footnotetext{
${ }^{4}$ Empirical evidence from both sides of the Atlantic suggests that intra-group inequality accounts for a sub-
} 
the insights from our analysis complement the respective results from the relatively new strand in the literature that introduces labor market imperfections into heterogeneous firms models in order to analyze how the firm-specific effects of trade translate into worker-specific wage effects. Since in these models only the most productive firms start exporting, employment as well as wage payments increase in these firms relative to their less productive competitors, which fosters wage inequality (see Egger and Kreickemeier, 2008; Helpman, Itskhoki, and Redding, 2008). ${ }^{5}$ In our setting, all firms equally benefit from access to the larger international market, while wage compression at the lower end of the technology distribution reduces intra-group wage inequality. This differential effect is well in line with recent empirical evidence on the development of wage inequality. For instance, relying on detailed UK data for the 1980s and the 1990s, Faggio, Salvanes, and Van Reenen (2007) conclude that individual wage inequality has generally increased and mainly so due to a rise of inequality between firms within the same industry, while the relevance of industry effects has declined over the observation period.

The remainder of the paper is organized as follows. Section 2 introduces the theoretical framework and shows how the general oligopolistic equilibrium framework of Neary (2009) has to be modified in order to account for firm-level union wage setting. Section 3 characterizes the autarky equilibrium and provides insights on how unemployment compensation and key parameters of the technology distribution affect the outcome in the closed economy. Section 4 considers trade between two symmetric countries and shows how the opening up to trade affects wage payments, profits, aggregate employment, and welfare. Beyond that, this section also provides insights on how trade changes the rent sharing between firm owners and workers as well as the distribution of income within these two groups of agents. In Section 5 we consider industry-level instead of firm-level unions and analyze to what extent our results depend on the degree of centralization in union wage setting. The last section concludes with a brief summary of the most important results.

\section{The model set-up}

We conduct our analysis in a general oligopolistic equilibrium (GOLE) framework, in which firms are small enough to rationally ignore their influence on aggregate variables, while they are large in their own industry and hence engage in strategic interactions with their competitors. Production and consumption is modeled along the lines of Neary (2009), who presents a workhorse model of the GOLE theory. However, we deviate from the baseline model by accounting for labor market imperfections due to the presence of labor unions (see Bastos and Kreickemeier, 2009). Furthermore, we distinguish between two types of agents: firm owners who receive profit income stantial part of overall income inequality (see Katz and Autor, 1999; Barth and Lucifora, 2006; Autor, Katz, and Kearney, 2008).

${ }^{5}$ Davis and Harrigan (2007) and Egger and Kreickemeier (2009) also consider intra-group wage inequality in a setting with heterogeneous firms. However, in these models relative wages between any two firms are determined by exogenous parameters, and hence they do not change in the process of globalization. 
and workers who receive wage income if employed and unemployment benefits otherwise. Details on our modeling strategy are outlined in Subsections 2.1-2.3.

\subsection{Preferences and consumer demand}

Preferences of the representative consumer are given by an additively separable utility function over a continuum of different goods, with the sub-utility function for each of these goods being quadratic. Denoting consumption of good $z$ by $x(z)$, utility can be written as

$$
U[\{x(z)\}]=\int_{0}^{1}\left[a x(z)-\frac{1}{2} b x(z)^{2}\right] d z .
$$

The budget constraint of the representative consumer is given by

$$
\int_{0}^{1} p(z) x(z) d z \leq I
$$

where $p(z)$ denotes the price of good $z$, and $I$ is aggregate income. Maximizing the utility in (1) subject to the budget constraint in (2) gives the inverse demand function for good $z$ :

$$
p(z)=\frac{1}{\lambda}[a-b x(z)],
$$

where $\lambda$ represents the Lagrangian multiplier of the respective optimization problem. The Lagrangian multiplier equals the marginal utility of income, which in our model is a function of the first and the second moment of prices,

$$
\mu_{1}^{p} \equiv \int_{0}^{1} p(z) d z \quad \text { and } \quad \mu_{2}^{p} \equiv \int_{0}^{1} p(z)^{2} d z
$$

respectively, as well as aggregate income, $I$ :

$$
\lambda[\{p(z)\}, I]=\frac{a \mu_{1}^{p}-b I}{\mu_{2}^{p}} .
$$

For a more detailed discussion on this issue, see Neary (2009).

\subsection{Technology and production}

We associate each good $z$ with a separate production sector, and hence consider a large number - or more precisely a continuum - of industries. Firms in all industries use labor to produce a homogeneous output and compete in quantities with the other firms in their industry. Output is linear in the labor input: $y=l / \alpha(z)$, with $\alpha(z)$ denoting the labor input coefficient in industry $z$. We abstract from investment costs for establishing the production facility and consider an exogenous number of firms, $n$, which is the same in each industry. 
Since the number of competitors within each industry is finite (or small), firms anticipate that they can influence industry-level variables, whereas they rationally take aggregate, economywide variables as given. As a consequence, they treat $\lambda$ parametrically and therefore face linear demand functions, according to (3). However, in contrast to a partial equilibrium model $\lambda$ is endogenous for the economy as a whole. In what follows, we choose the representative consumer's marginal utility of income as numéraire and set $\lambda$ equal to one. Considering product market clearing, $\sum_{i=1}^{n} y_{i}=x(z)$, and accounting for demand function (3), we can then write profits of firm $j$ in sector $z$ as

$$
\pi_{j}=\left[a-b \sum_{i=1}^{n} y_{i}-c_{j}(z)\right] y_{j},
$$

where $c_{j}(z)=\alpha(z) w_{j}$ denotes unit production costs. Throughout our analysis we focus on the case of positive supply of all firms and hence restrict our attention to parameter configurations that lead to $a>c_{j}(z)$ for all $j$ and $z$. Without loss of generality, we assume that industries are ranked such that $\alpha(z)$ is increasing in $z$.

\subsection{Labor market and endowments}

Regarding the determination of factor return $w_{j}$, we abandon the assumption of a perfectly competitive labor market as in Neary (2009) and assume that each industry is populated by $n$ firm-level unions, which unilaterally set wages, while firms keep the right-to-manage employment and choose $l_{j}=\alpha(z) y_{j}$ to maximize profits (6) conditional on $w_{j} .{ }^{6}$ The objective function of the labor union is given $\mathrm{by}^{7}$

$$
V_{j}=\left(w_{j}-\bar{w}\right) l_{j}
$$

with $\bar{w}$ denoting exogenous and constant unemployment benefits. Due to our choice of numéraire, the assumption of a constant $\bar{w}$ implies that unemployment compensation is continuously adjusted by policy makers to keep it constant in terms of the representative consumer's marginal utility $\lambda$. This assumption is useful for analytical tractability and has the nice implication that nominal unemployment benefits are increasing in aggregate income, which is well in line with empirical evidence. To complete the characterization of the labor market in our model, we finally assume that the country is populated by $L$ identical workers, each of them endowed with one unit of labor.

\footnotetext{
${ }^{6}$ In a previous version of this manuscript, we have considered a slightly more general framework with wage negotiations between firms and unions. However, since our main results do not hinge on the relative bargaining strength of firms and unions, we decided to stick to the more parsimonious model in which unions have all the bargaining power and therefore set wages unilaterally.

${ }^{7}$ Eq. (7) can either be interpreted as a Stone-Geary objective function, with unions simply maximizing rents and workers being perfectly mobile across firms and industries (see Bastos and Kreickemeier, 2009), or it can be interpreted as a utilitarian objective function, with union membership being predetermined (see Blanchard and Giavazzi, 2003). For an overview on different objective functions, see Oswald (1985).
} 


\section{Equilibrium in the closed economy}

The equilibrium outcome is determined by the solution of a two-stage problem with unions setting wages at stage one, and firms deciding upon output (employment) and purchases taking place at stage two. In Subsection 3.1, we solve the two-stage problem through backward induction and determine firm-level and industry-level variables. In Subsection 3.2 we solve for the general equilibrium and determine economy-wide variables.

\subsection{Solving for firm-level and industry-level variables}

At stage 2, firms choose profit-maximizing output (employment) levels. With firms anticipating that all their competitors in industry $z$ are identical and hence set the same output level, $y_{i}=y_{k}$ $\forall i, k \neq j$, the solution to the profit-maximization problem of firm $j$ is given by

$$
y_{j}=\frac{a+(n-1) \alpha(z) w_{i}-n \alpha(z) w_{j}}{b(n+1)}, \quad l_{j}=\frac{\alpha(z)\left[a+(n-1) \alpha(z) w_{i}-n \alpha(z) w_{j}\right]}{b(n+1)},
$$

according to (6). To solve the wage-setting problem of union $j$, we substitute $l_{j}$ from (8) in (7) and maximize the respective expression. Furthermore, considering symmetry, i.e. $w_{j}=w_{i}$, in the first-order condition $d V_{j} / d w_{j}=0$, we obtain ${ }^{8}$

$$
w_{j}=\frac{a+n \alpha(z) \bar{w}}{\alpha(z)(n+1)} \equiv w(z)
$$

While all firms within a single industry pay identical wages, since they do not differ in technology, it follows from (9) that sectors with higher labor productivity, i.e. a lower $\alpha(z)$, pay higher wages. This is intuitive, because firms in more productive sectors realize higher profits, all other things equal, and unionized labor participates in these higher profits due to a rent-sharing mechanism. ${ }^{9}$

The relative wage paid in two industries $z_{1}, z_{2}$, with $\alpha\left(z_{1}\right)>\alpha\left(z_{2}\right)$ is given by

$$
\frac{w\left(z_{2}\right)}{w\left(z_{1}\right)}=\frac{\alpha\left(z_{1}\right)\left[a+n \alpha\left(z_{2}\right) \bar{w}\right]}{\alpha\left(z_{2}\right)\left[a+n \alpha\left(z_{1}\right) \bar{w}\right]} \equiv \omega_{21} .
$$

It is immediate that $\omega_{21}>1$, because firms in sector $z_{2}$ use a more productive technology than firms in sector $z_{1}$. However, the sectoral wage differential, $\omega_{21}$, is smaller than the prevailing

\footnotetext{
${ }^{8}$ Two remarks are in order here. First, rent sharing implies $w(z)>\bar{w}$ if firms have market power and hence make positive profits. In the limiting case of $n \rightarrow \infty$, the model approaches to one with perfect competition in the goods market, with zero profits, and hence $w(z)=\bar{w}$ - provided the firms can hire the profit-maximizing amount of labor at $\bar{w}$. Second, substituting $w(z)$ from (9) into condition $a>c(z)$, it is immediate that $a>\alpha(1) \bar{w}$ is sufficient for an interior solution with a positive output level in all industries.

${ }^{9}$ There is indeed strong empirical support for the idea that more productive firms pay higher wages (see Hildreth and Oswald, 1997). This effect also survives if one controls for individual-specific factors, like education or experience. Furthermore, existing results suggest that a substantial part of the prevailing wage differential is due to industry effects (see Faggio, Salvanes, and Van Reenen, 2007). For instance, Blanchflower, Oswald, and Sanfey (1996, p. 241) conclude that "[c]hanges in industries' levels of prosperity have large effects upon workers' remuneration."
} 
productivity differential, due to the existence of unemployment compensation. Put differently, unemployment compensation leads to wage compression in our model. The impact of $\bar{w}$ on the wage differential in (10) is monotonic. A higher unemployment benefit raises the fallback income of workers. This leads to higher wage claims of unions, with the respective effect being stronger in sectors with lower productivity, according to (9). As a consequence, the wage differential $\omega_{21}$ shrinks if $\bar{w}$ goes up.

Substituting the wage rate from (9) in (8), gives equilibrium output and employment levels:

$$
y(z) \equiv \frac{n[a-\alpha(z) \bar{w}]}{b(n+1)^{2}}, \quad l(z) \equiv \frac{n \alpha(z)[a-\alpha(z) \bar{w}]}{b(n+1)^{2}} .
$$

The equilibrium price level then follows from (3):

$$
p(z)=\frac{(2 n+1) a+n^{2} \alpha(z) \bar{w}}{(n+1)^{2}} .
$$

Higher unemployment benefits, $\bar{w}$, lead to higher wage claims and thus lower output and employment at the firm level. This reduces competition in the goods market and leads to higher prices in all industries, according to (12). A higher labor input coefficient $\alpha(z)$ exhibits two counteracting effects on unit production costs. On the one hand, these costs increase for a given wage rate and, on the other hand, wage claims of unions become more moderate. The first (direct) effect dominates, and hence a higher $\alpha(z)$ is associated with higher unit production costs and a lower output level $y(z)$. The fall in $y(z)$ leads to an increase in the price level. Thus, in line with Neary (2009) outputs are lower and prices are higher in less productive industries. However, the respective output and price differential across industries is smaller if labor markets are unionized. Regarding employment, we can again distinguish two counteracting effects of an increase in $\alpha(z)$. On the one hand, it lowers output and thereby employment, $l(z)$, all other things equal. On the other hand, more labor is needed to produce a given level of output. In general, it is not clear which of the two counteracting effects dominates. To be more specific, we find that $d l(z) / d \alpha(z)>,=,<0$ if $a>,=,<2 \alpha(z) \bar{w}$. Hence, a positive employment effect of an increase in $\alpha(z)$ is the less likely, the higher is the level of unemployment benefits, $\bar{w}$.

In a final step, we can now substitute wage (9) for $w_{j}$ and output (11) for $y_{j}$ in (6), to determine equilibrium profits $\pi(z)$. With linear demand, equilibrium profits are proportional to the square of output, $\pi(z)=b y(z)^{2}$, so that the comparative static effects of changes in $\bar{w}$ and $\alpha(z)$ follow immediately from the respective effects on output $y(z)$. This completes our discussion on firm-level and industry-level variables.

\subsection{Unemployment, welfare, and income distribution}

With the insights from Subsection 3.1 at hand, we can now solve for the general equilibrium and determine the economy-wide variables. The first variable of interest is unemployment rate 
$u$, which is determined by

$$
u=1-\int_{0}^{1} \frac{n l(z)}{L} d z
$$

Substituting for $l(z)$ from (11) gives

$$
u=1-\frac{n^{2}\left[a \mu_{1}-\bar{w} \mu_{2}\right]}{b L(n+1)^{2}}
$$

with

$$
\mu_{1}=\int_{0}^{1} \alpha(z) d z, \quad \mu_{2}=\int_{0}^{1} \alpha^{2}(z) d z
$$

being the first and second moments of the technology distribution. From (14), we can deduce that $u>0$ holds if $b L$ is sufficiently large. On the one hand, economy-wide labor demand is independent of labor endowment, $L$. On the other hand, a higher $b$ makes labor demand less elastic, so that employment declines at any given wage rate. Throughout our analysis, we focus on a sufficiently high $b L$, such that involuntary unemployment exists in equilibrium. As noted in the last subsection, higher unemployment benefits, $\bar{w}$, lead to higher wage claims and to lower employment at the firm level. From (13), we see that this effect translates into a higher unemployment rate. This is intuitive and well in line with the existing literature on labor unions in general equilibrium models. To obtain insights into the role of labor productivity for unemployment rate $u$, it is useful to rewrite (13) in the following way

$$
u=1-\frac{n^{2}\left[\left(a-\mu_{1} \bar{w}\right) \mu_{1}-\sigma^{2} \bar{w}\right]}{b L(n+1)^{2}}
$$

with $\sigma^{2}=\mu_{2}-\mu_{1}^{2}$ being the variance of the technology distribution. Notably, $\sigma^{2}=0$ implies that all sectors produce with identical technology, and hence pay the same wage rate. In this case, a higher average labor input coefficient, $\mu_{1}$, has an ambiguous effect on the unemployment rate. It is positive for high levels of $\bar{w}$ and negative for low ones. This result is well in line with our insights from Section 3.1 that the impact of a change in $\alpha(z)$ on employment at the firm level is not clear in general and critically depends on the generosity of unemployment compensation.

If $\sigma^{2}>0$, labor productivity differs across industries. A mean-preserving spread in the technology distribution, i.e. an increase in $\sigma^{2}$ for a given $\mu_{1}$, raises the mass of sectors at the lower and upper bound of the $\alpha$-scale. From above we know that the existence of unemployment compensation compresses cross-sectoral wage differentials, and hence the average wage must increase if $\sigma^{2}$ goes up. However, with firms paying a higher wage on average, the labor market imperfection becomes more severe and unemployment increases.

A further aggregate variable of interest is welfare. Substituting $x(z)$ from (3) in (1), consid- 
ering $\lambda=1$ and ignoring constants, we obtain indirect utility of the representative consumer: $\tilde{U}=-\mu_{2}^{p}$. In view of (12), we can rewrite the latter expression in the following way:

$$
\begin{aligned}
\tilde{U} & =-\int_{0}^{1}\left[\frac{(2 n+1) a+n^{2} \alpha(z) \bar{w}}{(n+1)^{2}}\right]^{2} d z \\
& =-\frac{(2 n+1)^{2} a^{2}+n^{2} \bar{w} \mu_{1}\left[2(2 n+1) a+n^{2} \bar{w} \mu_{1}\right]+n^{4} \bar{w}^{2} \sigma^{2}}{(n+1)^{4}} .
\end{aligned}
$$

It is immediate that utilitarian welfare $\tilde{U}$ falls in $\bar{w}$. Higher unemployment benefits lower both total employment and aggregate output of industrial goods. This raises prices and therefore also $\mu_{2}^{p}$ with negative consequences for indirect utility of the representative consumer. Furthermore, we know from above that, all other things equal, a higher $\mu_{1}$ may exhibit a positive or negative impact on total employment. However, it definitely lowers aggregate output and hence raises the second moment of the price distribution $\mu_{2}^{p}$, with a negative effect on $\tilde{U}$. Finally, a meanpreserving spread in the technology distribution reduces total employment and leads to lower aggregate output. With a lower output, the second moment of prices increases and, as a consequence, welfare falls. It is notable that the welfare effect of a higher $\sigma^{2}$ differs from Neary (2009) who abstracts from adjustments in aggregate employment by considering a perfectly competitive labor market. In his model, a mean-preserving spread in the technology distribution shifts employment towards more productive sectors and thereby raises welfare, while in our framework the negative total employment effect reverses the welfare implications of a higher $\sigma^{2}$.

In a next step, we can explicitly solve for aggregate profits, $\Pi$, and aggregate wage income, $W$, with the respective values being given by

$$
\Pi=\frac{n^{3}\left[a^{2}-2 a \bar{w} \mu_{1}+\bar{w}^{2} \mu_{2}\right]}{b(n+1)^{4}}
$$

and

$$
W=\frac{n^{2}\left[a^{2}+(n-1) a \bar{w} \mu_{1}-n \bar{w}^{2} \mu_{2}\right]}{b(n+1)^{3}} .
$$

Since $\Pi$ and $W$ are expressed in terms of marginal utility, changes in these variables lack a clear economic interpretation. Hence, we do not further analyze these aggregates but rather look at the ratio of average profits, $\tilde{\pi} \equiv \Pi / n$, and average wages $\tilde{w}=W /[(1-u) L]$, to obtain a measure for inter-group income inequality. Considering (13), (16), (17) and denoting the profit-wage ratio by $\xi \equiv \tilde{\pi} / \tilde{w}$, we obtain

$$
\xi=\frac{n^{2}}{b(n+1)^{3}} \frac{\left[a^{2}-2 a \bar{w} \mu_{1}+\bar{w}^{2} \mu_{2}\right]\left[a \mu_{1}-\bar{w} \mu_{2}\right]}{a^{2}+(n-1) a \bar{w} \mu_{1}-n \bar{w}^{2} \mu_{2}} .
$$

This ratio approaches zero if firms have no market power, i.e. in the limiting case of $n \rightarrow \infty$. 
With perfect competition firms make zero profits, while the common wage rate equals the unemployment compensation, $\bar{w}$. Otherwise, $\xi$ is strictly positive and it may exceed one if both the unemployment compensation and the number of competitors are not too high. A higher $\bar{w}$ raises union wage claims and hence $\tilde{w}$. At the same time, $\tilde{\pi}$, shrinks, implying that the profitwage ratio in (18) falls if unemployment compensation becomes more generous. Furthermore, in the case of identical industries $\left(\sigma^{2}=0\right)$, a common increase in the labor input coefficient $\mu_{1}$ lowers profits per firm as well as union wage claims, which are linked to profits due to rent sharing at the firm level. Hence, there are two counteracting effects on the profit-wage ratio, and it is in general not clear which of these two effects dominates. Finally, with wage compression due to unemployment compensation, a mean-preserving spread in the technology distribution, i.e an increase in $\sigma^{2}$ for a given $\mu_{1}$, raises both average profits and average wages, thereby rendering the net impact on the profit-wage differential ambiguous.

For a complete picture of income inequality, we additionally need to account for the crosssectoral distribution of profits and the personal income distribution of workers, as two measures of intra-group income inequality. With a continuous distribution of profit and wage income, it is a necessary first step to find an adequate summary statistics. The two most commonly used metrics in this respect are the Gini and the Theil index. Both of these indices share one important property: they are based on the Lorenz curve. Hence, instead of choosing one particular index, we can directly look at the Lorenz curve in the subsequent analysis.

The Lorenz curve for profit income is given by ${ }^{10}$

$$
\mathfrak{J}(\bar{z}) \equiv \frac{a^{2} \bar{z}-2 a \bar{w} \int_{1-\bar{z}}^{1} \alpha(z) d z+\bar{w}^{2} \int_{1-\bar{z}}^{1} \alpha^{2}(z) d z}{a^{2}-2 a \bar{w} \mu_{1}+\bar{w}^{2} \mu_{2}}
$$

and plotted in Figure 1. $\mathfrak{J}(\bar{z})$ has the usual properties: it is increasing and convex in $\bar{z}$. In the borderline case of identical productivity levels in all industries, i.e. $\sigma^{2}=0$, the Lorenz curve coincides with the diagonal of the Lorenz curve diagram, implying that profits are equally distributed across industries. Consequently, a pari passu increase in all productivity levels, i.e. an increase in $\mu_{1}$ for $\sigma^{2}=0$, does not influence profit income distribution. To the contrary, a mean-preserving spread in the technology distribution shifts the Lorenz curve downwards, implying that profits are unequally distributed across sectors if $\sigma^{2}>0$. Furthermore, a higher $\bar{w}$ shifts the Lorenz curve downwards, i.e. it lowers $\mathfrak{J}(\bar{z})$ for any given $\bar{z} \in(0,1)$, and hence raises cross-sectoral profit inequality. Higher unemployment benefits induce higher wage claims, according to $(9)$, which reduces average profits $\tilde{\pi}$. However, with $\sigma^{2}>0$, the negative profit effect is not equally strong in all industries. As outlined above, unemployment benefits lead to wage compression, and hence the increase in union wage claims as well as the decline in profits is more pronounced in industries with low productivity, i.e. a high $\alpha(z)$. This makes the

\footnotetext{
${ }^{10}$ Details on how the inequality measures in this subsection are determined and a formal discussion on their properties are deferred to the appendix.
} 
cross-sectoral profit distribution more unequal.

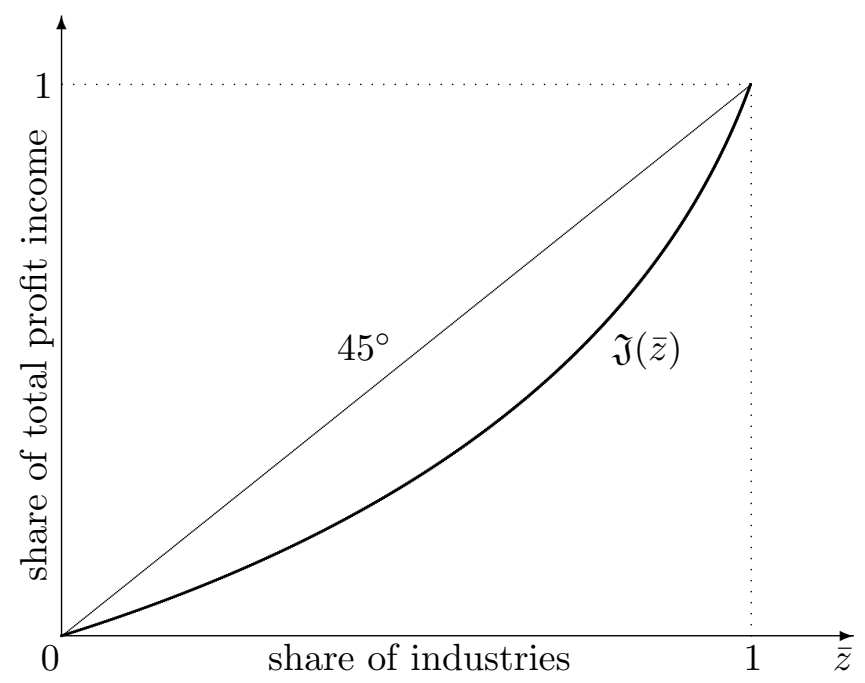

Figure 1: The Lorenz curve for profit income

The Lorenz curve for wage income is slightly more complicated than the one for profit income and characterized by the following two equations:

$$
\mathfrak{L}(\bar{z}) \equiv \frac{a^{2} \bar{z}+(n-1) a \bar{w} \int_{1-\bar{z}}^{1} \alpha(z) d z-n \bar{w}^{2} \int_{1-\bar{z}}^{1} \alpha^{2}(z) d z}{a^{2}+(n-1) a \bar{w} \mu_{1}-n \bar{w}^{2} \mu_{2}}
$$

and

$$
\rho(\bar{z}) \equiv \frac{a \int_{1-\bar{z}}^{1} \alpha(z) d z-\bar{w} \int_{1-\bar{z}}^{1} \alpha^{2}(z) d z}{a \mu_{1}-\bar{w} \mu_{2}},
$$

where the former equation determines the share of wage income that accrues to workers in industries $z \geq \bar{z}$, while the latter equation determines the share of production workers employed in industry $z \geq \bar{z}: \bar{\rho} \equiv \rho(\bar{z})$. Substituting $\rho^{-1}(\bar{\rho})$ from (21) for $\bar{z}$ in (20), gives the Lorenz curve for labor income $\mathfrak{M}(\bar{\rho}) \equiv \mathfrak{L}(\bar{z}(\bar{\rho}))$, which is depicted in Figure 2. As formally shown in the appendix, $\mathfrak{M}(\bar{\rho})$ is increasing and convex in $\bar{\rho}$. In the borderline case of $\sigma^{2}=0$, we have $\bar{z}=\bar{\rho}$. In this case, the Lorenz curve coincides with the diagonal of the Lorenz curve diagram, implying that wage income is equally distributed among production workers, irrespective of the size of $\mu_{1}$. If $\sigma^{2}>0$, the existence of labor unions leads to cross-sectoral wage inequality of $e x$ ante identical workers.

With $\sigma^{2}>0$, unemployment compensation becomes a crucial determinant of the wage distribution and an increase in $\bar{w}$ affects shape and position of the Lorenz curve through two different channels of influence. On the one hand, higher unemployment benefits lead to higher wage payments in all sectors, with the respective increase being more pronounced in less productive 


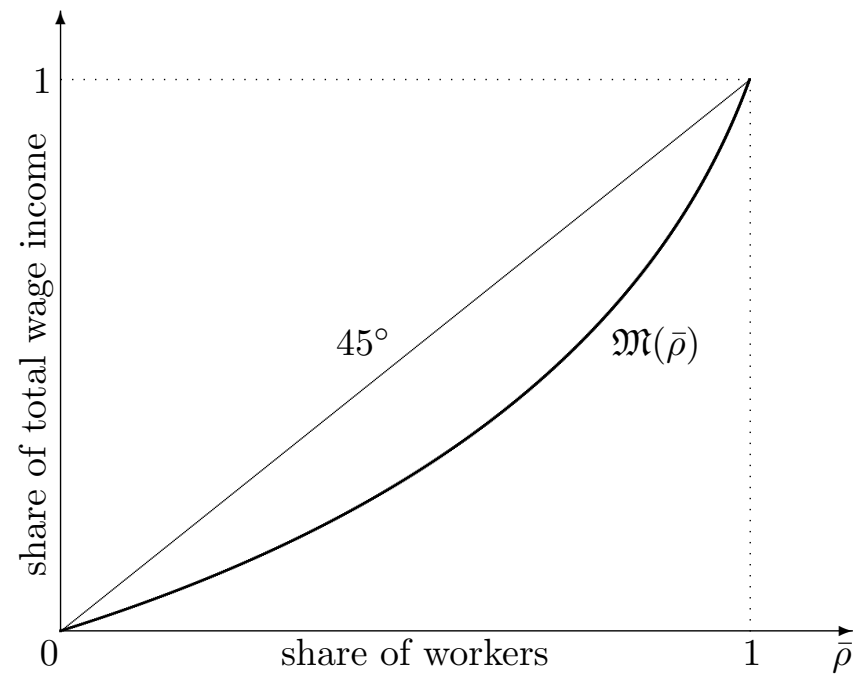

Figure 2: The Lorenz curve for wage income

industries (see Eqs. (9) and (10)). This lowers the cross-sectoral wage differential and hence renders the wage distribution more equal. On the other hand, the higher labor costs lead to a decline of employment in all sectors, with the relative employment between two industries increasing in favor of the more productive one. This increases the cross-sectoral wage inequality ceteris paribus. Unfortunately, we are not able to determine the impact of a higher $\bar{w}$ on the distribution of wage income for arbitrary levels of unemployment benefits. However, in the appendix we show that introducing a small positive $\bar{w}$ unambiguously lowers wage income inequality. ${ }^{11}$ This completes our discussion of the closed economy.

\section{The open economy}

In this section, we consider trade between two countries, whose economies are as described in Section 2. We abstract from any trade impediments and assume that goods markets are fully integrated, while labor markets remain internationally segmented and workers are immobile across countries. Furthermore, to facilitate our analysis we assume that the two countries under consideration are fully symmetric in all respects.

In the open economy, aggregate demand for output of sector $z$ can be determined by maximizing utility of the representative world consumer subject to his/her budget constraint. This

\footnotetext{
${ }^{11}$ In order to see whether this result holds more generally, we have conducted numerical simulation exercises for two concrete specifications of $\alpha(z): \alpha(z)=e^{z}$ and $\alpha(z)=1+z^{2}$. These simulation exercises indicate that, at least for the two considered specifications, the inequality reducing effect of an increase in $\bar{w}$ extends to positive levels of unemployment benefits.
} 
gives inverse demand for good $z$ :

$$
p(z)=\frac{1}{\lambda}[a-\tilde{b} x(z)]
$$

where $\tilde{b} \equiv b / 2$ implies that consumer demand is more elastic in the open economy than under autarky. With this insight at hand, we can now proceed in total analogy to the closed economy, when determining the trade equilibrium. Again, we start our analysis with the characterization of firm and industry-wide variables and compare our findings for the open economy with the respective results under autarky.

\subsection{Firm-level and industry-level variables in the open economy}

Solving the maximization problem of firm-level unions gives wage rate

$$
w^{t}(z)=\frac{a+2 n \alpha(z) \bar{w}}{\alpha(z)(2 n+1)} .
$$

Comparing $\left(9^{\prime}\right)$ with (9), it is immediate that $w^{t}(z)<w^{a}(z)$, where superscripts $t$ and $a$ are introduced in order to distinguish between trade and autarky variables, respectively. There are three effects that can be distinguished. First, the number of competitors as well as the mass of consumers doubles when a country starts trading with a symmetric partner country. In line with textbook oligopoly models, we can thus conclude that for given wages the opening up to trade leads to higher output and hence higher labor demand at the firm level. All other things equal, this provides an incentive for unions to set higher wages. Second, the increased competition in the goods market lowers profits and hence wage claims of unions by means of a standard rentsharing argument. Third, labor demand is more elastic in the open economy. This affects the trade-off between higher wages and higher employment in union objective (7) and implies that unions are more cautious about negative employment effects when increasing their wage claims. In sum, the latter two effects dominate the former one, so that trade liberalization disciplines unions and leads to more moderate wage setting.

The strength of this wage dampening effect is industry-specific and depends on the prevailing productivity level. To shed further light on the role of productivity for the impact of trade on union wage setting, we can look at the wage differential between two industries $z_{1}$ and $z_{2}$, with $\alpha\left(z_{1}\right)>\alpha\left(z_{2}\right)$ :

$$
\omega_{21}^{t}=\frac{\alpha\left(z_{1}\right)\left[a+2 n \alpha\left(z_{2}\right) \bar{w}\right]}{\alpha\left(z_{2}\right)\left[a+2 n \alpha\left(z_{1}\right) \bar{w}\right]}
$$

Comparing the latter with the respective ratio in the closed economy, we obtain $\omega_{21}^{t}<\omega_{21}^{a}$, implying that the cross-sectoral wage differential shrinks if an economy opens up for trade. This is intuitive, as the existence of unemployment compensation causes wage compression, and hence 
the decline in wages due to the opening up to trade is less pronounced in industries with low productivity. ${ }^{12}$

Regarding output and employment in the open economy, we can calculate

$$
y^{t}(z)=\frac{4 n[a-\alpha(z) \bar{w}]}{b(2 n+1)^{2}}, \quad l^{t}(z) \equiv \frac{4 n \alpha(z)[a-\alpha(z) \bar{w}]}{b(2 n+1)^{2}} .
$$

On the one hand, firms expand activity at given wages and, on the other hand, wages decline. Since both effects go into the same direction, it is immediate that firms operate at a larger scale in the open than in the closed economy. Substituting $x(z)=2 n y^{t}(z)$ from $\left(11^{\prime}\right)$ in $\left(3^{\prime}\right)$, we can conclude that the price in the open economy,

$$
p^{t}(z)=\frac{(4 n+1) a+4 n^{2} \alpha(z) \bar{w}}{(2 n+1)^{2}},
$$

is lower than the respective price under autarky, $p^{a}(z)$. This confirms the key finding of Brander (1981) that trade exhibits a pro-competitive effect if an oligopolistic market structure with firms competing in quantities prevails in the product market.

A final industry level variable we are interested in are industry-wide profits within either economy, $n \pi^{t}(z)$. With the number of local producers being constant, the impact of trade liberalization on industry-wide profits is fully characterized by the respective impact on firmlevel profits, which are given by $\pi^{a}(z)=b\left[y^{a}(z)\right]^{2}$ and $\pi^{t}(z)=(b / 2)\left[y^{t}(z)\right]^{2}$ in the closed and the open economy, respectively. Substituting the output levels from (11) and (11'), the following result is immediate. Profits are higher in the free trade equilibrium than under autarky if the number of competitors is sufficiently small. ${ }^{13}$ There are two counteracting effects at work. On the one hand, there is stronger competition in the open economy, implying that profits at the firm as well as the industry level shrink. For given wages, this effect is counteracted but not dominated by the increase in the number of consumers. On the other hand, unions set lower wages in the open economy, thereby providing an additional source for profit gains. It turns out that the second effect is stronger than the first one if the market power of firms is sufficiently large.

Before turning to a characterization of aggregate variables and a comparison of these variables with their counterparts in the closed economy, we summarize our results on firm-level and industry-level trade effects in the following proposition.

Proposition 1 A shift from autarky to free trade lowers wages as well as consumer prices,

\footnotetext{
${ }^{12}$ In the borderline case of $\bar{w}=0$, we obtain $\omega_{21}^{t}=\omega_{21}^{a}=\alpha\left(z_{2}\right) / \alpha\left(z_{1}\right)$, according to (10) and $\left(10^{\prime}\right)$.

${ }^{13}$ Note first that $\pi^{t}(z)>,=,<\pi^{a}(z)$ is equivalent to $8 /(2 n+1)^{4}>,=,<1 /(n+1)^{4}$, according to $(11),\left(11^{\prime}\right)$ and the respective expressions for firm level profits under autarky and free trade. Noting that $8(n+1)^{4} /(2 n+1)^{4}=1$ has a unique solution in $\mathbb{R}^{+}$at $\bar{n} \approx 2.14261$, with $8(n+1)^{4} /(2 n+1)^{4}>,=,<1$ if $\bar{n}>,=,<n$, confirms the respective result in the text. Restricting $n$ to integer values, we can conclude from this that firm owners are better-off in the free trade equilibrium if either a monopolistic $(n=1)$ or a duopolistic $(n=2)$ market structure prevails in the autarky equilibrium.
} 
while employment and output increase at the firm as well as the industry level. The impact on firm-level and industry-level profits is positive (negative) if the number of competitors is small (large).

\subsection{Aggregate variables in the open economy}

In this subsection we close the general equilibrium model and study aggregate variables in the open economy. The first variable of interest is the unemployment rate, which is determined in analogy to the closed economy and, using $l^{t}(z)$ from $\left(11^{\prime}\right)$ instead of $l^{a}(z)$ from (11), it is given by

$$
u^{t}(z)=1-\frac{4 n^{2}\left[a \mu_{1}-\bar{w} \mu_{2}\right]}{b L(2 n+1)^{2}}
$$

Intuitively, due to a positive employment stimulus at the firm level, the unemployment rate must be lower under free trade than under autarky. This result contributes to the ongoing debate on whether product market liberalization is a substitute for labor market deregulation. In line with Spector (2004), we find that stronger competition reduces wage claims of unions and increases total employment in the economy. However, there is a notable difference between product market liberalization in terms of entry of new firms in the domestic market (deregulation) and product market liberalization in terms of competition from foreign producers. In the former case, profits fall pari passu with wages, while in the latter case, firms may be better off if their market power is significant. Hence, the two policies are similar with respect to their labor market implications, while they may differ substantially in their product market implications.

Changes in aggregate employment and output also exhibit an impact on utilitarian welfare. Noting from above that welfare is measured by the representative consumer's indirect utility, $\tilde{U}=-\mu_{2}^{p}$, we obtain

$$
\begin{aligned}
\tilde{U}^{t} & =-\int_{0}^{1}\left[\frac{(4 n+1) a+4 n^{2} \alpha(z) \bar{w}}{(2 n+1)^{2}}\right]^{2} d z \\
& =-\frac{(4 n+1)^{2} a^{2}+8 n^{2} \bar{w} \mu_{1}\left[(4 n+1) a-n^{2} \bar{w} \mu_{1}\right]+8 n^{4} \bar{w}^{2} \sigma^{2}}{(2 n+1)^{4}}
\end{aligned}
$$

according to $\left(12^{\prime}\right)$. Comparing $\tilde{U}^{t}$ and $\tilde{U}^{a}$, proves existence of gains from trade due to a fall in consumer prices, i.e. $p^{t}(z)<p^{a}(z) \forall z$. While this result is well in line with the positive welfare effects in Neary (2009), there remains a crucial difference between the mechanisms at work. With perfect labor markets, there are no gains from trade if (i) the two economies are identical in all respects and (ii) all industries utilize the same production technology. In such a featureless economy increased competition shifts income from firms to workers but leaves aggregate output and hence total real income unaffected. In our framework, opening up to trade lowers union wage claims and hence reduces involuntary unemployment. This increases output and lowers 
consumer prices, thereby providing a welfare stimulus even if $\sigma^{2}=0$ implies symmetric industries in both economies. Notably, the welfare effects in this paper also differ from those in Bastos and Kreickemeier (2009), who - similar to us - consider union wage setting in a general oligopolistic equilibrium model. However, with unions being active only in a subset of industries, all workers find a job and hence aggregate employment and output effects cannot materialize in their setting. Nonetheless, there are gains from trade in the Bastos and Kreickemeier (2009) framework, even if countries are identical and all industries use the same technology. The reason is that if sectors differ in their labor market institutions, their wage costs and prices differ as well. In such a setting, the opening up to trade reduces the wage premium in unionized industries and hence the variance of consumer prices across sectors declines. This raises welfare even though aggregate output stays constant in Bastos and Kreickemeier (2009).

While a comparison of $(15)$ and $\left(15^{\prime}\right)$ reveals that the economy as a whole is better off in the open as compared to the closed economy, this does not mean that all individuals equally benefit from a movement towards free trade. For instance, those who are newly employed in the open economy gain relative to those who stay in their old job. Furthermore, firm owners in highly productive industries may gain or lose relative to firm owners in less productive industries as well as relative to their employees. To determine the distributional effects of a movement from autarky to free trade, we do not discuss all these cases separately, but rather look at summary statistics. In particular, we consider three different measures of income inequality: (i) the ratio between average profits and average wages, $\xi=\tilde{\pi} / \tilde{w}$; (ii) the Lorenz curve for profit income, $\mathfrak{J}$; and (iii) the Lorenz curve for wage income, $\mathfrak{M}$. We start with an analysis of the trade effects on inter-group inequality.

In the open economy, aggregate profit and wage income are given by

$$
\Pi^{t}=\frac{8 n^{3}\left[a^{2}-2 a \bar{w} \mu_{1}+\bar{w}^{2} \mu_{2}\right]}{b(2 n+1)^{4}}
$$

and

$$
W^{t}=\frac{4 n^{2}\left[a^{2}+(2 n-1) a \mu_{1} \bar{w}-2 n \bar{w}^{2} \mu_{2}\right]}{b(2 n+1)^{3}}
$$

respectively. In view of $\left(13^{\prime \prime}\right),\left(16^{\prime}\right)$ and $\left(17^{\prime}\right)$, the profit-wage ratio is then given by

$$
\xi^{t}=\frac{8 n^{2}}{(2 n+1)^{3}} \frac{\left[a^{2}-2 a \bar{w} \mu_{1}+\bar{w}^{2} \mu_{2}\right]\left[a \mu_{1}-\bar{w} \mu_{2}\right]}{a^{2}+(2 n-1) a \bar{w} \mu_{1}-2 n \bar{w}^{2} \mu_{2}},
$$

Comparing (18) and $\left(18^{\prime}\right)$, we can conclude that inter-group inequality is larger in the open than in the closed economy, i.e. $\xi^{t}>\xi^{a}$, if the number of competitors in either economy is small. As formally shown in the appendix, $n \leq 2$ is sufficient for an increase in inter-group inequality after trade liberalization. This is intuitive, as we already know that the opening up to trade lowers 
wages, while it raises profits if the market power of incumbent firms is large (see above). To the contrary, if the number of competitors is sufficiently high, not only profit income but also inter-group inequality is reduced by a shift from autarky to free trade.

To determine intra-group income inequality among firm owners and workers, we can look at the position and shape of the respective Lorenz curve. The Lorenz curve of profit income in the open economy is given by

$$
\mathfrak{J}^{\mathfrak{t}}(\bar{z}) \equiv \frac{a^{2} \bar{z}-2 a \bar{w} \int_{1-\bar{z}}^{1} \alpha(z) d z+\bar{w}^{2} \int_{1-\bar{z}}^{1} \alpha^{2}(z) d z}{a^{2}-2 a \bar{w} \mu_{1}+\bar{w}^{2} \mu_{2}},
$$

which equals $\mathfrak{J}^{\mathfrak{a}}(\bar{z})$ in (19). Hence, a movement from autarky to trade does not affect the crosssectoral distribution of profits. Note that with linear demand profits are proportional to the square of output (or employment). Regarding relative employment across industries, we can distinguish two effects. On the one hand, firms in more productive industries produce at a less elastic segment of the labor demand curve than firms in industries with a high $\alpha(z)$. This implies that a proportional reduction in wages induces a more than proportional expansion of employment in industries with a high $\alpha(z)$. On the other hand, wages do not fall proportionally, according to Eq. $\left(10^{\prime}\right)$. This counteracts and exactly offsets the former effect, so that relative employment and hence relative output levels remain unaffected when a country moves from autarky to free trade. However, with relative output remaining unaffected, relative profits do not change either, and hence the cross-sectoral profit distribution under autarky equals the respective distribution under free trade.

As a final element of our analysis, we now characterize the Lorenz curve for intra-group income inequality among production workers in the open economy. To determine the respective curve, we proceed as under autarky and combine the Lorenz curve for cross-sectoral wage inequality, which is given by

$$
\mathfrak{L}^{t}(\bar{z}) \equiv \frac{a^{2} \bar{z}+(2 n-1) a \bar{w} \int_{1-\bar{z}}^{1} \alpha(z) d z-2 n \bar{w}^{2} \int_{1-\bar{z}}^{1} \alpha^{2}(z) d z}{a^{2}+(2 n-1) a \bar{w} \mu_{1}-2 n \bar{w}^{2} \mu_{2}},
$$

with the employment distribution across industries, which is characterized by the same $\rho(\bar{z})$ as in the closed economy, because - as noted above - relative employment between any two sectors remains unaffected when a country opens up for trade. Considering Eq. (21) and substituting $\bar{z}(\bar{\rho})=\rho^{-1}(\bar{\rho})$ in $\left(20^{\prime}\right)$ gives the Lorenz curve for income inequality among production workers: $\mathfrak{M}^{t}(\rho)=\mathfrak{L}^{t}(\bar{z}(\bar{\rho}))$. Intuitively, since relative employment of any two industries stays constant, while the wage premium of more productive industries shrinks, according to $\left(10^{\prime}\right)$, intra-group wage inequality must fall when two symmetric countries move from autarky to free trade. This concludes the formal discussion and we summarize the main insights from our analysis in this section in the following proposition.

Proposition 2 A shift from autarky to free trade stimulates aggregate employment and welfare. 
Furthermore, it does not affect income inequality among firm owners, while it lowers income inequality among production workers. The impact on inter-group inequality between firm owners and production workers is not clear in general and critically depends on the market power of firms in the closed economy. If competition in the closed economy is strong (weak), firm owners will lose (gain) relative to production workers when a country opens up for trade.

\section{Extension: Industry-level unions}

While firm-level unions are broadly accepted to be a fairly good description of the UK as well as the US labor market, it is an empirical fact that wage setting is significantly more centralized in continental Europe (OECD, 2004). This suggests to analyze the robustness of our results regarding changes in the degree of centralization in union wage setting. For this purpose, we modify our previous modeling approach and assume that unions are organized at the industry instead of the firm level. ${ }^{14}$ The industry-level union is national in scope and sets a uniform wage rate for all domestic firms in the respective sector. Its objective is to maximize $V_{C}=(w-\bar{w}) n l$ instead of (7), where subscript $C$ refers to the centralized wage setting scenario in this section. Using $w_{i}=w_{j}$ in (8) and substituting the respective expression in $V_{C}$ gives union objective under autarky as a function of the wage rate. Maximizing this objective yields

$$
w_{C}^{a}(z)=\frac{a+\alpha(z) \bar{w}}{2 \alpha(z)} .
$$

When maximizing their rents, unions take into account the trade-off involved in setting higher wages. On the one hand, choosing a higher wage rate raises $V_{C}$ for a given employment level. On the other hand, a higher wage rate lowers employment and thus $V_{C}$ indirectly. This second effect is more pronounced if unions are organized at the firm level, because a higher firm-specific wage rate reduces competitiveness of the producer in the second-stage output game. Such a strategic motive of setting lower wages does not exist if unions are organized at the industry level and hence industry-level unions set higher wages than firm-level ones. ${ }^{15}$ This can be confirmed by comparing Eqs. (9) and (22). The absence of this strategic motive in the wage setting of unions also explains why the autarky wage rate does not depend on the number of competitors if unions are organized at the industry level.

\footnotetext{
${ }^{14}$ In the interest of readability we present the main results of this section in an informal way, putting particular emphasis on the economic intuition for the respective effects. Details on how the results have been derived are deferred to a technical supplement which is available upon request.

${ }^{15}$ This is a common result in the literature on union wage setting and is well in line with the empirical observation by Calmfors and Driffill (1988) that the relationship between the degree of centralization in the organization of unions and union wage claims is hump-shaped, with wages being highest if unions are organized at the industry level.
} 
In the open economy, the rent-maximizing wage rate of the industry-level union is given by

$$
w_{C}^{t}(z)=\frac{a+\alpha(z) \bar{w}(n+1)}{\alpha(z)(n+2)} .
$$

The wage rate in $\left(22^{\prime}\right)$ is higher than the respective wage rate chosen by firm-level unions in $\left(9^{\prime}\right)$. However, in contrast to the closed economy, $w_{C}^{t}$ depends on the number of competitors. The reason is that unions are confined to national labor markets, so that two unions are active within one industry in the open economy. This introduces a strategic motive for setting lower wages, because lower wage costs increase the competitiveness of domestic producers vis-á-vis foreign competitors in the second-stage output game. The strength of this strategic motive depends on the number of competitors and it is less pronounced with industry-level unions than in the case of firm-level wage setting.

From our considerations above we can conclude that unions set higher wages if organized at the industry instead of the firm level, irrespective of whether the economy is in autarky or has opened up for trade. This implies that an industry-wide organization of unions leads to lower output and higher unemployment, and therefore exhibits higher welfare costs than a more decentralized organization of unions at the firm level. Regarding income inequality, we can first note that higher wage claims induce a fall in profits, and hence the profit-wage ratio is lower if unions are organized at the industry instead of the firm level. Put differently, with industry-level unions workers can skim a larger share of rents - while the total amount of rents is smaller than in the case of firm-level wage setting. Income inequality among firm owners remains unaffected by a switch towards a more centralized organization of unions. The reason is that all sectors are equally affected by this change in the structure of wage setting, thereby leaving relative employment across industries unchanged. With profits being proportional to the square of output, it is hence immediate that the degree of centralization in the organization of unions has no bearing on profit income inequality. Finally, intra-group inequality is more pronounced if unions are organized at the industry level. While relative employment across sectors does not depend on the degree of centralization in union wage setting, the wage increase associated with a switch from firm-level to industry-level unions is more pronounced in sectors with high labor productivity, i.e. in those sectors in which the unemployment benefit is a less important determinant of the union wage claim. It is this second effect which explains that intra-group wage inequality is more pronounced if unions are organized at the industry instead of the firm level. ${ }^{16}$

\footnotetext{
${ }^{16}$ The finding that inter-group inequality is smaller while unemployment is higher if unions are organized industry wide is well in line with the empirical observation that the US economy is characterized by high intergroup inequality and low unemployment while the opposite is true in Europe. Krugman (1994) associates the differential experience with two sides of the same medal and argues that different institutional settings on the two sides of the Atlantic are responsible for this outcome. Our model additionally indicates that intra-group wage inequality is more pronounced in continental Europe, where wage bargaining is more centralized than in the US. However, this hypothesis cannot be confronted with empirical evidence, because cross-country comparisons on size and development of intra-group inequality are so far not available to the best of our knowledge.
} 
Regarding the movement from autarky to trade, there is only one notable difference between the setting with industry-level unions and the baseline scenario with wage setting at the firm level. If unions are organized at the industry level, a strategic motive for setting lower wages in order to improve the position of firms in the output competition does only materialize in the open economy but not under autarky. Hence, the wage depressing effect of trade is more pronounced than in a setting with firm-level unions, implying that in the model variant with industry-level unions all firms experience a profit gain from trade, irrespective of the competitive environment in the closed economy. In all other respects, the movement from autarky to trade exhibits qualitatively the same effects under both regimes of union wage setting, and hence we can conclude that the main insights from our analysis are robust to changes in the degree of centralization in union wage setting.

\section{Concluding remarks}

This paper presents a general oligopolistic equilibrium model with a unit mass of heterogeneous industries and imperfect labor markets due to the existence of firm-level unions. In this setting we investigate how a movement from autarky to free trade with a symmetric partner country affects the product and labor market outcome. In particular, we show that unions face a more elastic labor demand curve and hence reduce their wage claims, while firms increase their output levels in the open economy. Beyond that, the results from our analysis suggest that taking the existence of labor market frictions seriously is crucial for reaching a better understanding of the profit effects of trade liberalization. Due to the decline in wage payments, firm owners may benefit from a movement towards free trade, at least if their market power under autarky is sufficiently high. This qualifies the wide-spread view that trade is a substitute for domestic product market deregulation, as stronger competition in international markets should lower the ability of firm owners to earn excessive profits. As pointed out in this paper, such a reasoning is only valid if the labor market is perfectly competitive, while it may be wrong in the context of union wage setting.

While the above effects would also arise in a partial equilibrium setting, the general equilibrium framework provides additional novel insights upon adjustments in economy-wide variables. In this respect, our analysis shows that the opening up to trade lowers the incentive of unions to set excessive wages and therefore raises employment and welfare. Aside from this positive efficiency effect, trade also reduces income inequality among production workers, while leaving income inequality among firm owners unaffected. This implies that trade uncouples the distribution of profits from the distribution of wages even though the existence of unions leads to rent sharing. Finally, inter-group inequality between firm owners and production workers may be amplified or reduced by a movement from autarky to trade, with the respective effect crucially depending on the market power of firms prior to the integration process. 
We hope that embedding a unionized oligopoly model into a general equilibrium framework can help to improve our understanding on how trade liberalization affects product and labor market outcomes. While accounting for general equilibrium feedback effects makes our analysis more suitable for explaining real world problems, there are still simplifying assumptions that limit the potential of our model for deriving concrete policy recommendations. For instance, by focussing on symmetric countries, we cannot analyze whether unilateral policy reforms that aim at deregulating the labor and/or the product market can be successful in an open economy. Furthermore, the assumption of symmetric countries also implies that all trade is intra-industry, while it rules out a differential impact on exporting and importing industries, which has shown to be important empirically (see Katz and Summers, 1989; Grey, 1993). Second, by assuming that wage setting in both economies is organized at the same level (within firms or industrywide), our model cannot capture the empirical fact that the organization of labor unions differs substantially across countries and it excludes a detailed discussion on labor market linkages in international markets. While extending the model in either of these directions is clearly beyond the scope of this paper, considering the respective modifications may be a worthwhile task for future research.

\section{References}

Autor, D. H., L. F. Katz, and M. S. Kearney (2008): "Trends in U.S. Wage Inequality: Revising the Revisionists," Review of Economics and Statistics, 90(2), 300-323.

Barth, E. A., And C. Lucifora (2006): "Wage Dispersion, Markets and Institutions: The Effects of the Boom in Education on the Wage Structure," IZA Discussion Paper, No. 2181.

Bastos, P., and U. Kreickemeier (2009): "Unions, competition and international trade in general equilibrium," Journal of International Economics, 79(2), 238-247.

Bernanke, B. S. (2007): "The Level and Distribution of Economic Well-Being," Speech before the Greater Omaha Chamber of Commerce, Omaha, Nebraska, February 6, 2007: http://www.federalreserve.gov/newsevents/speech/Bernanke20070206a.htm.

Blanchard, O., and F. Giavazzi (2003): "Macroeconomic Effects of Regulation and Deregulation in Goods and Labor Markets," Quarterly Journal of Economics, 118(3), 879-907.

Blanchflower, D. G., A. J. Oswald, and P. Sanfey (1996): "Wages, Profits, and RentSharing," Quarterly Journal of Economics, 111(1), 227-251.

Brander, J. A. (1981): "Intra-Industry Trade in Identical Commodities," Journal of International Economics, 11(1), 1-14. 
Calmfors, L., And J. Driffill (1988): "Bargaining Structure, Corporatism and Macroeconomic Performance," Economic Policy, 3(6), 14-61.

Davidson, C., L. Martin, and S. Matusz (1999): "Trade and Search Generated Unemployment," Journal of International Economics, 48(2), 271-299.

Davis, D. R., and J. Harrigan (2007): "Good Jobs, Bad Jobs, and Trade Liberalization," NBER Working Paper, No. 13139.

Dickens, W. T., And L. F. Katz (1987): "Inter-Industry Wage Differences and Theories of Wage Determination," NBER Working Paper, No. 2014.

Du Caju, P., F. Rycx, and I. Tojerow (2008): "Rent-Sharing and the Cyclicality of Wage Differentials," CEB Working Paper, No. 08/035.

Eckel, C., And H. EgGer (2009): "Wage Bargaining and Multinational Firms," Journal of International Economics, 77(2), 206-214.

Egger, H., P. Egger, and J. R. Markusen (2009): "International Welfare and Employment Linkages Arising from Minimum Wages," NBER Working Paper, No. 15196.

Egger, H., and U. Kreickemeier (2008): "Fairness, Trade, and Inequality," CESifo Working Paper, No. 2344.

(2009): "Firm Heterogeneity and the Labour Market Effects of Trade Liberalisation," International Economic Review, 50(1), 187-216.

Faggio, G., K. Salvanes, and J. Van Reenen (2007): "The Evolution of Inequality in Productivity and Wages: Panel Data Evidence," NBER Working Paper, No. 13351.

Grey, A. (1993): "Interindustry Wage Differentials in Manufacturing: Rents and Industrial Structure," Canadian Journal of Economics, 26(3), 525-535.

Helpman, E., O. Itskhoki, and S. Redding (2008): "Inequality and Unemployment in a Global Economy," NBER Working Paper, No. 14478.

Hildreth, A. K. G., And A. J. Oswald (1997): "Rent-Sharing and Wages: Evidence from Company and Establishment Panels," Journal of Labor Economics, 15(2), 318-337.

HuizingA, H. (1993): "International Market Integration and Union Wage Bargaining," Scandinavian Journal of Economics, 95(2), 249-255.

Katz, L. F., And D. H. Autor (1999): "Changes in the Wage Structure and Earnings Inequality," in Handbook of Labor Economics. Volume 3A, ed. by O. Ashenfelter, and D. Card, pp. 1463-1555. Elsevier Science, North-Holland, Harvard U. 
Katz, L. F., and L. H. Summers (1989): "Can Inter-Industry Wage Differentials Justify Strategic Trade Policy?," NBER Working Paper, No. 2739.

Krueger, A. B., And L. H. Summers (1988): "Efficiency Wages and the Inter-industry Wage Structure," Econometrica, 56(2), 259-293.

Krugman, P. (1994): "Past and Prospective Causes of High Unemployment," Federal Reserve Bank of Kansas City Economic Review, 79(4), 23-43.

Lommerud, K. E., F. Meland, and L. Sørgard (2003): "Unionised Oligopoly, Trade Liberalisation and Location Choice," Economic Journal, 113(490), 782-800.

Matusz, S. J. (1996): "International Trade, the Division of Labor, and Unemployment," International Economic Review, 37(1), 71-84.

Melitz, M. J. (2003): "The Impact of Trade on Intra-industry Reallocations and Aggregate Industry Productivity," Econometrica, 71(6), 1695-1725.

Mezzetti, C., And E. Dinopoulos (1991): "Domestic Unionization and Import Competition," Journal of International Economics, 31(1-2), 79-100.

NAYLOR, R. (1998): "International Trade and Economic Integration When Labour Markets Are Generally Unionised," European Economic Review, 42(7), 1251-1267. (1999): "Union Wage Strategies and International Trade," Economic Journal, 109(452), $102-125$.

NEARY, J. P. (2009): "International Trade in General Oligopolistic Equilibrium," unpublished manuscript, University of Oxford.

OECD (2004): OECD Employment Outlook. OECD,Paris.

(2007): OECD Employment Outlook. OECD, Paris.

Oswald, A. J. (1985): "The Economic Theory of Trade Unions: An Introductory Survey," Scandinavian Journal of Economics, 87(2), 160-193.

Plasman, R., I. Tojerow, and F. Rycx (2006): "Industry Wage Differentials, Unobserved Ability, and Rent-Sharing: Evidence from Matched Worker-Firm Data, 1995-2002," IZA Discussion Paper, No. 2387.

Scheve, K. F., and M. J. Slaughter (2001): Globalization and the perceptions of American workers. Institute for International Economics.

Sørensen, J. R. (1993): "Integration of Product Markets When Labour Markets Are Unionized," Recherches Economiques de Louvain, 59(4), 485-502. 
Spector, D. (2004): "Competition and the Capital-Labor Conflict," European Economic Review, 48(1), 25-38.

WäLde, K., And P. Weiss (2007): "International Competition, Downsizing and Wage Inequality," Journal of International Economics, 73(2), 396-406. 


\section{Appendix}

\section{The Lorenz curve for profit income in the closed economy: $\mathfrak{J}(\bar{z})$}

To determine the Lorenz curve for profit income, we first calculate aggregate profit income accruing to firms with a labor input coefficient higher than or equal to firms in industry $1-\bar{z}$. Substituting $y(z)$ from $(8)$ in $\pi(z)=b y(z)^{2}$, it is immediate that total profits in industry $z$, $\Pi(z) \equiv n \pi(z)$, are given by

$$
\Pi(z)=\frac{n^{3}[a-\alpha(z) \bar{w}]^{2}}{b(n+1)^{4}} .
$$

Adding up $\Pi(z)$ over all industries $z \geq 1-\bar{z}$ gives

$$
\begin{aligned}
\bar{\Pi}(\bar{z}) & =\int_{1-\bar{z}}^{1} \Pi(z) \\
& =\frac{n^{3}\left[a^{2} \bar{z}-2 a \bar{w} \int_{1-\bar{z}}^{1} \alpha(z) d z+\bar{w}^{2} \int_{1-\bar{z}}^{1} \alpha(z)^{2} d z\right]}{b(n+1)^{4}}
\end{aligned}
$$

with $\bar{\Pi}(1)$ being equal to economy-wide profit income $\Pi$ in (16). Since the number of firms is the same in all industries, $1-\bar{z}$ denotes the fraction of firms with profits lower than $\pi(1-\bar{z})$. Hence, the Lorenz curve for profit income is given by $\mathfrak{J}(\bar{z})=\bar{\Pi}(\bar{z}) / \Pi$, which can be reformulated to (19). Differentiating $\mathfrak{J}(\bar{z})$ and defining $\bar{\alpha} \equiv \alpha(1-\bar{z})$, gives

$$
\frac{d \mathfrak{J}(\bar{z})}{d \bar{z}}=\frac{a^{2}-2 a \bar{w} \bar{\alpha}+\bar{w}^{2} \bar{\alpha}^{2}}{a^{2}-2 a \bar{w} \mu_{1}+\bar{w}^{2} \mu_{2}}>0, \quad \frac{d^{2} \mathfrak{J}(\bar{z})}{d \bar{z}^{2}}=-\frac{2 \bar{w}[a-\bar{\alpha} \bar{w}]}{a^{2}-2 a \bar{w} \mu_{1}+\bar{w}^{2} \mu_{2}} \times \frac{d \alpha(1-\bar{z})}{d \bar{z}}>0,
$$

which proves that the Lorenz curve $\mathfrak{J}(\bar{z})$ has the standard properties: It is positively sloped and convex (in $\bar{z})$.

The comparative-static effects in the main text regarding changes in $\mu_{1}$ and $\sigma^{2}$ are immediate and need no further formal discussion. To determine the impact of an increase in unemployment compensation $\bar{w}$ on $\mathfrak{J}(\bar{z})$, we differentiate $d \mathfrak{J}(\bar{z}) / d \bar{z}$ with respect to $\bar{w}$. This gives

$$
\frac{d^{2} \mathfrak{J}(\bar{z})}{d \bar{z} d \bar{w}}=-2 \frac{\left(a \bar{\alpha}-\bar{\alpha}^{2} \bar{w}\right)\left(a^{2}-2 a \bar{w} \mu_{1}+\bar{w}^{2} \mu_{2}\right)-\left(a \mu_{1}-\bar{w} \mu_{2}\right)\left(a^{2}-2 a \bar{w} \bar{\alpha}+\bar{w}^{2} \bar{\alpha}^{2}\right)}{\left[a^{2}-2 a \bar{w} \mu_{1}+\bar{w}^{2} \mu_{2}\right]^{2}},
$$

which can be further simplified to

$$
\frac{d^{2} \mathfrak{J}(\bar{z})}{d \bar{z} d \bar{w}}=-\frac{2 a \bar{\alpha}(a-\bar{w} \bar{\alpha})}{\left[a^{2}-2 a \bar{w} \mu_{1}+\bar{w}^{2} \mu_{2}\right]^{2}} G(\bar{\alpha})
$$


with

$$
\begin{aligned}
G(\bar{\alpha}) & \equiv a\left(1-\frac{\mu_{1}}{\bar{\alpha}}\right)-\bar{w} \bar{\alpha}\left(\frac{\mu_{1}}{\bar{\alpha}}-\frac{\mu_{2}}{\bar{\alpha}}\right) \\
& =\int_{0}^{1}[a-\bar{w} \alpha(z)]\left(1-\frac{\alpha(z)}{\bar{\alpha}}\right) d z
\end{aligned}
$$

From this, we can conclude that $d^{2} \mathfrak{J}(\bar{z}) / d \bar{z} d \bar{w}>,=,<0$ if $0>,=,<G(\bar{\alpha})$. Notably, $G(\bar{\alpha})>0$ if $\bar{\alpha}=\alpha(1)$ or, equivalently $\bar{z}=0$, while $G(\bar{\alpha})<0$ if $\bar{\alpha}=\alpha(0)$, or equivalently $\bar{z}=1$. Furthermore, from differentiating (27) we can deduce that $G^{\prime}(\bar{\alpha})>0$ and hence $G^{\prime}(\bar{\alpha}) \times d \bar{\alpha} / d \bar{z}<0$. This however implies that $G(\bar{\alpha})=0$ has a unique solution in $\bar{z} \in(0,1)$, which we denote by $\bar{z}^{*}$. As a consequence, $G(\bar{\alpha})>0$ and thus $d^{2} \mathfrak{J}(\bar{z}) / d \bar{z} d \bar{w}<0$ if $\bar{z}<\bar{z}^{*}$, while $G(\bar{\alpha})<0$ and thus $d^{2} \mathfrak{J}(\bar{z}) / d \bar{z} d \bar{w}>0$ if $\bar{z}>\bar{z}^{*}$. ¿From this we can deduce that the Lorenz curve for $\bar{w}_{1}$ lies below the Lorenz curve for $\bar{w}_{0}$ if $\bar{w}_{1}>\bar{w}_{0}$, implying that higher unemployment benefits make the profit income distribution more unequal. This confirms the respective result in the text.

\section{The Lorenz curve for wage income in the closed economy: $\mathfrak{M}(\bar{\rho})$}

To determine the Lorenz curve for wage income, we need to combine two elements: the distribution of wage payments and the distribution of workers across industries. Starting with the first element, we can note that total wage payments of industry $z$ are given by $W(z) \equiv n l(z) w(z)$. In view of (9) and(11), this implies

$$
W(z)=\frac{n^{2}\left[a^{2}+(n-1) a \alpha(z) \bar{w}-n \alpha^{2}(z) \bar{w}^{2}\right]}{b(n+1)^{3}}
$$

Since industries are ranked according to their wages, with more productive industries paying higher ones, we can conclude that the cumulative wage income of workers who are employed in industries $z \geq 1-\bar{z}$, is given by

$$
\begin{aligned}
\bar{W}(\bar{z}) & \equiv \int_{1-\bar{z}}^{1} W(z) d z \\
& =\frac{n^{2}\left[a^{2} \bar{z}+(n-1) a \bar{w} \int_{1-\bar{z}}^{1} \alpha(z) d z-n \bar{w}^{2} \int_{1-\bar{z}}^{1} \alpha^{2}(z) d z\right]}{b(n+1)^{3}} .
\end{aligned}
$$

Notably, $\bar{W}(1)$ equals economy-wide labor income $W$ in (17). The ratio of labor income accruing to workers in industries $z \geq 1-\bar{z}$ is determined by $\mathfrak{L}(\bar{z}) \equiv \bar{W}(\bar{z}) / W$, which can be reformulated to $(20)$.

The second element we need to determine is the distribution of workers across industries. 
Total employment in industry $z$ is given by $L(z) \equiv n l(z)$. Substituting $l(z)$ from (11), we obtain

$$
L(z) \equiv \frac{n^{2} \alpha(z)[a-\alpha(z) \bar{w}]}{b(n+1)^{2}}
$$

Hence, cumulative employment in industries $z \geq 1-\bar{z}$ is given by

$$
\begin{aligned}
\bar{L}(\bar{z}) & \equiv \int_{1-\bar{z}}^{1} L(\bar{z}) d z \\
& =\frac{n^{2}\left[a \int_{1-\bar{z}}^{1} \alpha(z) d z-\bar{w} \int_{1-\bar{z}}^{1} \alpha^{2}(z) d z\right]}{b(n+1)^{2}},
\end{aligned}
$$

with $L(1)$ being equal to economy-wide employment

$$
(1-u) L=\frac{n^{2}\left[a \mu_{1}-\bar{w} \mu_{2}\right]}{b(n+1)^{2}}
$$

(see (13)). The ratio of workers who are employed in industries $z \geq 1-\bar{z}$ is then represented by $\rho(\bar{z})$ in (21). Denoting the function value of $\rho(\bar{z})$ by $\bar{\rho}$ and considering the inverse function $\bar{z}=\rho^{-1}(\bar{\rho})$ in $(20)$ - with the properties of this inverse function following from (21) - finally gives the Lorenz curve for wage income $\mathfrak{M}(\bar{\rho})$.

Differentiating $\mathfrak{M}(\bar{\rho})$ yields

$$
\begin{aligned}
\frac{d \mathfrak{M}(\bar{\rho})}{d \bar{\rho}} & =\frac{d \mathfrak{L}(\bar{z})}{d \bar{z}} \times \frac{d \bar{z}}{d \bar{\rho}} \\
& =\frac{a^{2}+(n-1) a \bar{\alpha} \bar{w}-n \bar{\alpha}^{2} \bar{w}^{2}}{a^{2}+(n-1) a \mu_{1} \bar{w}-n \mu_{2} \bar{w}^{2}} \times \frac{a \mu_{1}-\bar{w} \mu_{2}}{a \bar{\alpha}-\bar{w} \bar{\alpha}^{2}}
\end{aligned}
$$

and

$$
\frac{d^{2} \mathfrak{M}(\bar{\rho})}{d \bar{\rho}^{2}}=-\frac{\left[a \mu_{1}-\bar{w} \mu_{2}\right]^{2}\left[a \bar{\alpha}^{2} \bar{w}^{2}+a^{2}(a-2 \bar{w} \alpha)\right]}{\left[a^{2}+(n-1) a \bar{w} \mu_{1}-n \bar{w}^{2} \mu_{2}\right]^{2}\left[a \alpha-\bar{w} \bar{\alpha}^{2}\right]^{3}} \times \frac{d \bar{\alpha}}{d \bar{z}}
$$

where $\bar{\alpha}=\alpha(1-\bar{z})$ has been considered. Noting $d \bar{\alpha} / d \bar{z}<0$, the latter two equations confirm that $\mathfrak{M}(\bar{\rho})$ is a positively sloped and convex function of $\bar{\rho}$. While the results in the main text regarding the comparative-static effects of changes in the two technology parameters $\mu_{1}$ and $\sigma^{2}$ on $\mathfrak{M}(\bar{\rho})$ are immediate, the impact of higher unemployment compensation is less obvious and hence requires further discussion. To determine this impact, we differentiate $d \mathfrak{M}(\bar{\rho}) / d \bar{\rho}$ with 
respect to $\bar{w}$, which yields

$$
\begin{aligned}
\frac{d^{2} \mathfrak{M}(\bar{\rho})}{d \bar{\rho} d \bar{w}}= & \frac{d^{2} \mathfrak{L}(\bar{z})}{d \bar{z} d \bar{w}} \times \frac{d \bar{z}}{d \bar{\rho}}+\frac{d \mathfrak{L}(\bar{z})}{d \bar{z}} \times \frac{d^{2} \bar{z}}{d \bar{\rho} d \bar{w}} \\
= & \frac{a^{2}\left[(n-1) a\left(\bar{\alpha}-\mu_{1}\right)-2 n \bar{w}\left(\bar{\alpha}^{2}-\mu_{2}\right)\right]-n \bar{w}^{2}(n-1) a\left(\mu_{1} \bar{\alpha}^{2}-\bar{\alpha} \mu_{2}\right)}{\left[a^{2}+(n-1) a \mu_{1} \bar{w}-n \mu_{2} \bar{w}^{2}\right]^{2}} \times \frac{a \mu_{1}-\bar{w} \mu_{2}}{a \bar{\alpha}-\bar{w} \bar{\alpha}^{2}} \\
& +\frac{a^{2}+(n-1) a \bar{\alpha} \bar{w}-n \bar{\alpha}^{2} \bar{w}^{2}}{a^{2}+(n-1) a \mu_{1} \bar{w}-n \mu_{2} \bar{w}^{2}} \times \frac{a \bar{\alpha}\left(\mu_{1} \bar{\alpha}-\mu_{2}\right)}{\left[a \bar{\alpha}-\bar{w} \bar{\alpha}^{2}\right]^{2}} .
\end{aligned}
$$

Evaluating the latter expression at $\bar{w}=0$, we obtain

$$
\left.\frac{d^{2} \mathfrak{M}(\bar{\rho})}{d \bar{\rho} d \bar{w}}\right|_{\bar{w}=0}=\frac{\tilde{G}(\bar{\alpha})}{a \bar{\alpha}},
$$

with

$$
\begin{aligned}
\tilde{G}(\bar{\alpha}) & \equiv n \bar{\alpha} \mu_{1}-(n-1) \mu_{1}^{2}-\mu_{2} \\
& =\bar{\alpha} \int_{0}^{1}\left[(n-1) \mu_{1}+\alpha(z)\right]\left(1-\frac{\alpha(z)}{\bar{\alpha}}\right) d z
\end{aligned}
$$

Notably, $\tilde{G}(\bar{\alpha})>0$ if $\bar{\alpha}=\alpha(0)$, i.e. if $\bar{z}=1$, while $\tilde{G}(\bar{\alpha})<0$ if $\bar{\alpha}=\alpha(1)$, i.e. if $\bar{z}=0$. Furthermore, $\tilde{G}^{\prime}(\bar{\alpha})>0$ and, hence, $\tilde{G}^{\prime}(\bar{\alpha}) \times d \bar{\alpha} / d \bar{z}<0$. We can therefore safely conclude that $\tilde{G}(\bar{\alpha})=0$ has a unique solution in $\bar{z} \in(0,1)$, which we denote by $\bar{z}^{* *}$. Then, $d^{2} \mathfrak{M}(\bar{\rho}) /\left.d \bar{\rho} d \bar{w}\right|_{\bar{w}=0}>0$ if $\bar{z}<\bar{z}^{* *}$, while $d^{2} \mathfrak{M}(\bar{\rho}) /\left.d \bar{\rho} d \bar{w}\right|_{\bar{w}=0}<0$ if $\bar{z}>\bar{z}^{* *}$. This however implies that increasing unemployment benefits from zero to a small positive level lowers wage income inequality according to the Lorenz curve criterion, thereby confirming the respective result in the main text.

\section{A comparison of $\xi^{a}$ and $\xi^{t}$}

From a comparison of (18) and $\left(18^{\prime}\right)$, we can conclude that $\xi^{t}>,=,<\xi^{a}$ is equivalent to

$$
\frac{8}{(2 n+1)^{2}\left[a^{2}+(2 n-1) a \bar{w} \mu_{1}-2 n \bar{w}^{2} \mu_{2}\right]}>,=,<\frac{1}{(n+1)^{2}\left[a^{2}+(n-1) a \bar{w} \mu_{1}-n \bar{w}^{2} \mu_{2}\right]} .
$$

Rearranging terms and defining

$$
A(n) \equiv\left(\frac{2 n+2}{2 n+1}\right)^{3}, \quad B(n) \equiv \frac{a^{2}+(2 n-1) a \bar{w} \mu_{1}-2 n \bar{w}^{2} \mu_{2}}{a^{2}+(n-1) a \bar{w} \mu_{1}-n \bar{w}^{2} \mu_{2}}
$$

we can further note that $\xi^{t}>,=,<\xi^{a}$ is equivalent to $A(n)>,=,<B(n)$. In order to determine how the ranking of $A(n)$ and $B(n)$ depends on firm number $n$, we have to characterize the properties of these two functions. Straightforward calculations give $A(0)=8, \lim _{n \rightarrow \infty} A(n)=1$ and $A^{\prime}(n)<0$. Furthermore, we find $B(0)=1, \lim _{n \rightarrow \infty} B(n)=2$ and $B^{\prime}(n)>0$. This however implies that $A(n)=B(n)$ has a unique solution in $n$, which we denote by $n^{*}$. Then, 
$A(n)>B(n)$ and thus $\xi^{t}>\xi^{a}$ if $n<n^{*}$, whereas $A(n)<B(n)$ and thus $\xi^{t}<\xi^{a}$ if $n>n^{*}$. To confine the possible values of $n^{*}$, we can can evaluate $A(n)$ and $B(n)$ at $n=2$. This yields $A(2)=216 / 125=1.728$ and

$$
B(2)=\frac{a^{2}+3 a \bar{w} \mu_{1}-4 \bar{w}^{2} \mu_{2}}{a^{2}+a \bar{w} \mu_{1}-2 \bar{w}^{2} \mu_{2}}
$$

respectively. Rearranging terms, we find that $A(2)>,=,<B(2)$ is equivalent to

$$
0,728 a\left(a-\bar{w} \mu_{1}\right)>,=,<0,544 \bar{w} \mu_{1}\left(a-\bar{w} \frac{\mu_{2}}{\mu_{1}}\right) .
$$

However, noting $a>\bar{w} \mu_{1}$ and $\mu_{2}>\mu_{1}^{2}$, it is immediate that the right-hand-side of the latter expression is smaller than its left-hand side, so that $A(n)>B(n)$ or, equivalently, $\xi^{t}>\xi^{a}$ if $n \leq 2$ This confirms the respective result in the main text.

\section{The Lorenz curve for profit income in the open economy: $\mathfrak{J}^{t}(\bar{z})$}

To determine the Lorenz curve for profit income in the open economy, we follow the respective steps in the closed economy and first calculate

$$
\Pi^{t}(z)=\frac{8 n^{3}[a-\alpha(z) \bar{w}]^{2}}{b(2 n+1)^{4}}
$$

Adding up over all industries $z \geq 1-\bar{z}$ further implies

$$
\begin{aligned}
\bar{\Pi}^{t}(\bar{z}) & \equiv \int_{1-\bar{z}}^{1} \Pi(z) \\
& =\frac{8 n^{3}\left[a^{2} \bar{z}-2 a \bar{w} \int_{1-\bar{z}}^{1} \alpha(z) d z+\bar{w}^{2} \int_{1-\bar{z}}^{1} \alpha(z)^{2} d z\right]}{b(2 n+1)^{4}}
\end{aligned}
$$

with $\bar{\Pi}^{t}(1)$ being equal to aggregate profit income $\Pi^{t}$ in $\left(16^{\prime}\right)$. Hence, the Lorenz curve for profit income is given by $\mathfrak{J}^{t}(\bar{z})=\bar{\Pi}^{t}(\bar{z}) / \Pi^{t}$, which can be reformulated to $\left(19^{\prime}\right)$ and hence confirms that the Lorenz curve for profit income remains unaffected by the movement from autarky to free trade.

\section{The Lorenz curve for wage income in the open economy: $\mathfrak{M}^{t}(\bar{\rho})$}

In analogy to the closed economy, we first calculate total wage payments of industry $z$, which in views of $\left(9^{\prime}\right)$ and $\left(11^{\prime}\right)$ is given by

$$
W^{t}(z)=\frac{4 n^{2}\left[a^{2}+(2 n-1) a \alpha(z) \bar{w}-2 n \alpha^{2}(z) \bar{w}^{2}\right]}{b(2 n+1)^{3}}
$$


With industries being ranked according to their wages, the cumulative wage income of workers who are employed in industries $z \geq 1-\bar{z}$, is given by

$$
\bar{W}^{t}(\bar{z})=\frac{4 n^{2}\left[a^{2} \bar{z}+(2 n-1) a \bar{w} \int_{1-\bar{z}}^{1} \alpha(z) d z-2 n \bar{w}^{2} \int_{1-\bar{z}}^{1} \alpha^{2}(z) d z\right]}{b(2 n+1)^{3}},
$$

where $\bar{W}^{t}(1)$ equals economy-wide labor income $W^{t}$ in $\left(17^{\prime}\right)$. The ratio of labor income accruing to workers in industries $z \geq 1-\bar{z}$ is determined by $\mathfrak{L}^{t}(\bar{z}) \equiv \bar{W}(\bar{z}) / W$, which can be reformulated to $\left(20^{\prime}\right)$.

Furthermore, considering $\left(11^{\prime}\right)$, total employment in industry $z$ can be written as

$$
L^{t}(z) \equiv \frac{4 n^{2} \alpha(z)[a-\alpha(z) \bar{w}]}{b(2 n+1)^{2}}
$$

and cumulative employment in industries $z \geq 1-\bar{z}$ is given by

$$
\bar{L}^{t}(\bar{z})=\frac{4 n^{2}\left[a \int_{1-\bar{z}}^{1} \alpha(z) d z-\bar{w} \int_{1-\bar{z}}^{1} \alpha^{2}(z) d z\right]}{b(2 n+1)^{2}} .
$$

The ratio of workers who are employed in industries $z \geq 1-\bar{z}$ is given by $\rho(\bar{z})$ in $(21)$ and hence equals the respective ratio in the closed economy. Combining $\left(20^{\prime}\right)$ and (21), finally gives the Lorenz curve for wage income $\mathfrak{M}^{t}(\bar{\rho})$.

Noting that the distribution of workers across industries, $\rho(\bar{z})$, is the same in the closed and the open economy, it follows from $(20)$ and $\left(20^{\prime}\right)$ that the movement from autarky to free trade affects the Lorenz curve only through an increase in the number of competitors (which doubles). We can hence learn the impact of trade liberalization on wage income inequality from differentiating (33) with respect to $n$. This gives

$$
\begin{aligned}
\frac{d^{2} \mathfrak{M}(\bar{\rho})}{d \bar{\rho} d n}=\frac{\left[a \bar{w} \bar{\alpha}-\bar{w}^{2} \bar{\alpha}^{2}\right]\left[a^{2}+(n-1) a \mu_{1} \bar{w}-n \mu_{2} \bar{w}^{2}\right]}{\left[a^{2}+(n-1) a \mu_{1} \bar{w}-n \mu_{2} \bar{w}^{2}\right]^{2}} \times \frac{a \mu_{1}-\bar{w} \mu_{2}}{a \bar{\alpha}-\bar{w} \bar{\alpha}^{2}} \\
-\frac{\left[a \bar{w} \mu_{1}-\bar{w}^{2} \bar{\mu}_{2}\right]\left[a^{2}+(n-1) a \bar{\alpha} \bar{w}-n \bar{\alpha}^{2} \bar{w}^{2}\right]}{\left[a^{2}+(n-1) a \mu_{1} \bar{w}-n \mu_{2} \bar{w}^{2}\right]^{2}} \times \frac{a \mu_{1}-\bar{w} \mu_{2}}{a \bar{\alpha}-\bar{w} \bar{\alpha}^{2}}
\end{aligned}
$$

Tedious but straightforward calculations yield

$$
\frac{d^{2} \mathfrak{M}(\bar{\rho})}{d \bar{\rho} d n}=\frac{a \bar{w} \bar{\alpha}(a-\bar{w} \bar{\alpha}) G(\bar{\alpha})}{\left[a^{2}+(n-1) a \mu_{1} \bar{w}-n \mu_{2} \bar{w}^{2}\right]^{2}} \times \frac{a \mu_{1}-\bar{w} \mu_{2}}{a \bar{\alpha}-\bar{w} \bar{\alpha}^{2}},
$$

with $G(\bar{\alpha})$ being defined in (27). Considering the properties of $G(\bar{\alpha})$ from above, we can therefore conclude that a higher $n$ lowers wage income inequality according to the Lorenz criterion. This confirms the respective result concerning the impact of trade liberalization on wage income inequality in the main text. 